\title{
CUIDADO HUMANIZADO ÀS GESTANTES, PARTURIENTES E PUÉRPERAS: ANÁLISE TEMÁTICA DA CONCEPÇÃO DOS PROFISSIONAIS DE SAÚDE
}

\author{
Beatriz Castro Souza Capelanes ${ }^{1}$, Maryelle Peres da Silva Santos', Katia Terezinha Alves \\ Rezende $^{2}$ e Mara Quaglio Chirelli² \\ 1,2 Faculdade de Medicina de Marília (Famema), Brasil, beatrizcscp@gmail.com; peresmaryelle@gmail.com \\ katialvesrezende@gmail.com; marachirelli@gmail.com
}

\begin{abstract}
Resumo. Introdução: o movimento de humanização do parto ocorre muito lentamente e enfrenta resistências para a implementação de um novo modelo de cuidado no país. Objetivo: analisar a concepção dos profissionais de saúde sobre o cuidado humanizado prestado às mulheres no préparto, parto e pós-parto no cotidiano de um hospital de grande porte do interior do estado de São Paulo, Brasil. Método: pesquisa com abordagem qualitativa, por meio de entrevista com profissionais de saúde e Análise de Conteúdo, Modalidade Temática. Resultados e Discussão: constatou-se nuances do cuidado humanizado e ferramentas para a promoção do cuidado humanizado, sendo importante rever as estratégias de implementação das propostas do Projeto Apice On, incorporando a Educação Permanente em Saúde como estratégia de reflexão e reconstrução das práticas em saúde. Conclusão: sugere-se ampliar a investigação com as usuárias do serviço e seus familiares, utilizando a análise temática, que revelou as nuances do contexto e as concepções dos profissionais.
\end{abstract}

Palavras-chave: Parto Humanizado; Saúde Materno-infantil; Pesquisa Qualitativa; Hospitais.

HUMANIZED CARE FOR PREGNANT WOMEN, PARTURIENTS AND PUERPERAL WOMEN: THEMATIC ANALYSIS OF THE CONCEPTION OF HEALTH PROFESSIONALS

\begin{abstract}
Introduction: the humanization of childbirth movement occurs very slowly and faces resistance in the implementation of a new model of care in the country. Goal: to analyze the conception of health professionals about the humanized care offered to women in pre-parturition, parturition and post-parturition in the daily routine of a large hospital in a city inland of the State of São Paulo, Brazil. Method: research with a qualitative approach, through interviews with health professionals and Content Analysis, Thematic Mode. Results and Discussion: nuances of humanized care and tools for the promotion of humanized care were found. It is important to review the implementation strategies of the Apice On Project proposals, incorporating Permanent Education in Health as a strategy for reflection and reconstruction of health practices. Conclusion: it is suggested to expand the investigation with the users of the service and their families using the thematic analysis, which revealed the nuances of the context and the conceptions of the professionals.
\end{abstract}

Keywords: Humanizing Delivery; Maternal and Child Health; Qualitative Research; Hospitals.

\section{INTRODUÇÃO}

O avanço das práticas e políticas de saúde na área da obstetrícia contribuiu com a melhoria dos indicadores de morbimortalidade materna e perinatal. Entretanto, permitiu a concretização de um modelo que considera a gravidez, o parto e o nascimento como doenças e não como processos fisiológicos; expondo mulheres e recém-nascidos a altas taxas de intervenções e colocando-os em situações de risco. Uma constatação disso, é que 
a melhoria dos indicadores foi comprometida no Brasil, não atingindo, ainda, a meta do quinto Objetivo de Desenvolvimento do Milênio em reduzir em três quartos a Razão da Mortalidade Materna durante o intervalo de 1990 a 2015 (Ministério da Saúde [MS], 2017b).

Nos últimos vinte anos, houve um aumento significativo na aplicação de práticas para iniciar, acelerar, encerrar, regular e monitorar o parto. A crescente medicalização do trabalho de parto fere a capacidade da própria mulher de parir e afeta negativamente sua experiência nesse processo. Assim recomendações foram divulgadas pela Organização Mundial da Saúde (OMS) abordando aspectos específicos do manejo do trabalho de parto e nascimento e contemplando as principais causas de morbimortalidade materna e neonatal em resposta às necessidades dos países (World Health Organization [WHO], 2018). As diretrizes fornecem uma ferramenta adequada de consulta para os profissionais: a prática clínica baseada em evidências. Sendo, esta, formada pela informação baseada na melhor pesquisa científica, habilidade/experiência clínica dos profissionais de saúde e expectativas/necessidades únicas das mulheres e suas famílias. Com a união dessas três exigências, tem-se uma ferramenta focada na qualidade do cuidado e uma potente aliada na tomada de decisão nas atividades diárias dos profissionais de saúde (MS, 2017b).

Mas ainda existe um distanciamento entre ciência e o cuidado obstétrico. $O$ excesso de intervenções desnecessárias, a baixa incorporação das boas práticas disponíveis, a falta de transparência nas ações e a concentração de poder na tomada de decisões favorece a banalização de procedimentos não recomendados (Lansky et al., 2019; Vilela, 2017). Além disso, o aumento do uso de intervenções, na ausência de indicações claras, demonstra e agrava a falta de equidade em saúde entre os locais que possuem mais recursos disponíveis daqueles que possuem menos. Assim, em alguns contextos, intervenções estão sendo fornecidas tarde demais para as mulheres e, em outros, muito cedo (WHO, 2018). Práticas obsoletas e sem indicações afetam principalmente a população de menor renda, evidenciando a iniquidade na sociedade brasileira (Lansky et al., 2019).

Os hospitais universitários deveriam ser os primeiros lugares a absorver os avanços no conhecimento científico, inovando e aplicando as melhores práticas. No entanto, estão entre os locais mais resistentes à mudança no cuidado obstétrico. O modelo tecnocrático ainda persiste e continua sendo adotado nessas instituições, fazendo com que os profissionais ali formados reproduzam e perpetuem o modelo inadequado (Mendes \& Rattner, 2020; Diniz, Rattner, d'Oliveira, Aguiar \& Niy, 2018). O processo de mudança é complexo, árduo e lento, 
principalmente pela dificuldade de integrar a prática aos direitos humanos, às perspectivas de gênero e à presença de outras figuras na condução do trabalho de parto que não só a do médico (Diniz et al., 2018).

O crescente movimento de humanização do parto e nascimento propiciou mudanças no sistema obstétrico brasileiro, dominado pelo modelo tecnicista e intervencionista, e contribuiu para a emergência de iniciativas sociais e governamentais (Picheth, Crubellate \& Verdu, 2018). No Brasil, desde a década de 1990, o movimento social teve um papel importante em desencadear as primeiras mudanças e obteve sucesso na busca da parceria com o MS uma vez que a disseminação das práticas humanizadas exige que políticas públicas se tornem disponíveis nacionalmente. Desde 1993, a Rede Brasileira pela Humanização do Parto e Nascimento (ReHuNa) atua como uma organização da sociedade civil na divulgação de cuidados obstétricos e perinatais baseados em evidências científicas. Uma das conquistas desse movimento foi a Lei $\mathrm{n}^{\circ} 11.108 / 2005$, que garante um acompanhante durante o trabalho de parto, nascimento e no período pós-natal (Diniz et al., 2018).

O Programa de Humanização do Pré-natal e Nascimento (PHPN) (MS, 2000) influencia a criação da Rede Cegonha (MS, 2011), instituída para modificar o cuidado prestado nos serviços e promover a adequação da atenção ao parto, com gradativa implementação de um modelo humanizado. Nesse contexto, o MS implementa o Projeto Apice On (Aprimoramento e Inovação no Cuidado e Ensino em Obstetrícia e Neonatologia), para contribuir com a efetivação e disseminação de boas práticas formativas de atenção e gestão, pautadas nos princípios da humanização. Pretende-se produzir impacto em toda a rede, a partir da qualificação baseada em evidências científicas nos campos de cuidado ao parto e nascimento, de atenção às mulheres em situações de violência sexual, abortamento e aborto legal, e de planejamento reprodutivo pós-parto e pós aborto (MS, 2017a).

A instituição pesquisada está inserida, desde 2011, na Rede Cegonha e, recentemente, em novembro de 2017, também passou a integrar a rede de hospitais que participam do Projeto Apice On. Diante disso, pergunta-se: "como os profissionais compreendem o processo de humanização no cuidado às mulheres durante o pré-parto, parto e pós-parto". Portanto, temse como objetivo analisar a concepção dos profissionais de saúde sobre o cuidado humanizado às mulheres durante o pré-parto, parto e pós-parto no cotidiano de um hospital de grande porte do interior do estado de São Paulo, Brasil. 
Assim, esta investigação justifica-se não só em evidenciar possíveis contradições no cuidado obstétrico e, simultânea e consequentemente, estimular reflexões nos entrevistados, mas também em ser um compromisso com a justiça às mulheres e seus filhos que têm seus direitos desrespeitados. Ao se investigar as diferentes concepções, tem-se como intenção, que, no futuro, novas propostas de trabalho possam ser elaboradas, abordando a humanização do parto e nascimento a partir dos desafios encontrados.

\subsection{Referencial Teórico}

Ayres (2009) destaca que ao se falar sobre cuidado, humanização ou integralidade, abordase o conjunto de princípios pautados na relação entre o sujeito paciente e o profissional de saúde, mas não se restringe ao plano dessas relações. Depende, também, dos rearranjos técnicos ou gerenciais das instituições, tratando-se de um projeto existencial de caráter político. É uma construção de interações mais simétricas entre os diversos sujeitos envolvidos nesse cuidado em saúde, permitindo a compreensão mútua e o consenso. Essas interações substituem o sentido único dos discursos dos profissionais por um diálogo entre profissionais, serviços, usuários e comunidades.

No referencial de gestão em saúde, o sentido é mais amplo e compreende o compartilhamento na participação, produção e responsabilização nos resultados da humanização, trazendo mais autonomia do usuário, fortalecendo sua condição de sujeito e promovendo relações simétricas entre profissionais e usuários.

A expressão humanização do parto e nascimento denomina: uma concepção de maternidade e nascimento, um movimento social, uma política pública, um modelo de assistência obstétrica e uma defesa dos direitos humanos e da dignidade das mulheres e seus filhos. Essa discussão, iniciada no Brasil em 1990, demarca uma oposição à obstetrícia hegemonicamente praticada no país e propõe o diálogo com o humanismo presente na formação ética das profissões envolvidas, sobretudo, da Medicina e da Enfermagem; a defesa da ciência como princípio da prática, com ênfase no estudo sobre o ciclo gravídicopuerperal; e a educação para mulheres e profissionais de saúde, os quais devem incluir os desejos e as necessidades das pacientes na tomada das decisões. Isso fortalece os direitos das mulheres, sua autonomia e integridade corporal (Bourguignon \& Grisotti, 2018; Lokugamage \& Pathberiya, 2017). 
Dessa forma, os profissionais de saúde devem adotar e adaptar recomendações que fornecem uma base sólida para prestar às mulheres e seus bebês um cuidado ampliado, centrado na pessoa e baseado em evidências científicas (WHO, 2018).

\section{METODOLOGIA}

A fim de alcançar o objetivo mencionado acima, essa pesquisa optou por uma abordagem qualitativa, para aprofundar a compreensão dos processos, sujeitos, relações sociais e estruturas, que, por sua vez, são depositárias de significados, aspirações, crenças e valores (Minayo, 2014). Nesse sentido, o trabalho de campo apresentou-se como uma possibilidade de conseguir uma aproximação com o cuidado obstétrico e de criar conhecimento, partindo da realidade presente em um hospital universitário de grande porte do interior do estado de São Paulo, Brasil.

Os participantes foram os profissionais de saúde pertencentes à equipe de referência da unidade de internação e do centro obstétrico.

Dessa forma, foram incluídos na investigação médicos ginecologistas/obstetras e anestesiologistas, médicos residentes do $2^{\circ}$ e $3^{\circ}$ ano de Ginecologia e Obstetrícia, enfermeiros, técnicos de enfermagem e auxiliares de enfermagem que realizavam atividades na instituição pesquisada por, no mínimo, seis meses.

Os médicos residentes do primeiro ano de Ginecologia e Obstetrícia foram excluídos porque possuíam tempo de experiência inferior a seis meses.

Utilizou-se roteiro na entrevista semiestruturada para coletar os dados, sendo composto pela caracterização dos participantes e por questões norteadoras: "O que você considera ser cuidado humanizado às gestantes, às puérperas e aos bebês?"; "Dê exemplos de condutas e técnicas que você considera ser humanizadas"; "Você promove esse cuidado humanizado? Se não, por quê? Se sim, como?"; "Você acredita que o cuidado humanizado é um direito da mulher e do bebê? Se não, por quê? Se sim, por quê?".

As entrevistas foram realizadas por duas pesquisadoras. Um piloto foi elaborado para a padronização da estratégia de coleta de dados frente aos disparadores e para a formação das entrevistadoras, com a supervisão de uma orientadora. 
As pesquisadoras identificaram os profissionais da equipe de referência pertencentes à unidade de saúde em questão, sendo abordados no local de trabalho, porém em lugar reservado. As entrevistadoras se identificaram e explicaram sobre a pesquisa. Possuindo disponibilidade em participar, os profissionais assinaram o Termo de Consentimento Livre e Esclarecido (TCLE).

A coleta de dados compreendeu o período de abril a dezembro/2019. Atingiu-se a saturação com 24 entrevistas, ou seja, com o conteúdo obtido foi possível compreender a lógica interna do grupo de profissionais em relação ao objeto de estudo (Minayo, 2014). Os diálogos, com duração média de 40 minutos, foram gravados e transcritos na íntegra pelas pesquisadoras e validados pela orientadora.

A técnica de análise de dados empregada foi a Análise de Conteúdo, Modalidade Temática, segundo Minayo, Deslandes e Gomes (2016).

Para tanto, realizou-se uma pré-análise, a qual consistiu em transcrever as entrevistas na íntegra, permitindo a impregnação do conteúdo das falas, bem como a retomada dos pressupostos e dos objetivos da pesquisa.

Esse momento possibilitou ter uma visão de conjunto, apreender as particularidades e definir um esquema de classificação inicial composto pelas categorias: como realiza o cuidado, definição de cuidado humanizado e direito da mulher, potencialidades da prática do cuidado humanizado, desafios da prática do cuidado humanizado e estratégias, Projeto Apice On, protocolos para o cuidado.

Em seguida, explorou-se o material, com distribuição dos trechos das falas e, posteriormente, diálogo com as partes de um trecho de uma dada classe.

A partir de então, elaborou-se uma descrição desses fragmentos de depoimentos. Por meio de inferência, identificou-se os núcleos de sentido, sendo agrupados em temas. Nesse artigo, serão apresentados os temas "nuances do cuidado humanizado" e "ferramentas para a promoção do cuidado humanizado" e seus respectivos núcleos de sentido, segundo o quadro 1. 
Quadro 1 - Núcleos de sentido e temas, 2019.

\begin{tabular}{|c|c|}
\hline Núcleos de Sentido & Temas \\
\hline $\begin{array}{l}\text { Cuidado humanizado atrelado a considerar a mulher em suas diferentes } \\
\text { dimensões }\end{array}$ & \multirow{8}{*}{$\begin{array}{l}\text { Nuances do cuidado } \\
\text { humanizado }\end{array}$} \\
\hline Cuidado humanizado atrelado a considerar os desejos da mulher & \\
\hline Cuidado humanizado atrelado à capacidade de promover orientação e informação & \\
\hline Cuidado humanizado atrelado ao embasamento em evidências científicas & \\
\hline Cuidado humanizado atrelado ao afeto e educação & \\
\hline Cuidado humanizado atrelado ao acesso a exames complementares & \\
\hline Médico é indispensável na promoção do cuidado humanizado & \\
\hline Contestação do termo humanização do cuidado & \\
\hline $\begin{array}{l}\text { Relação entre estrutura organizacional hospitalar e viabilização do cuidado } \\
\text { humanizado }\end{array}$ & \multirow{4}{*}{$\begin{array}{l}\text { Ferramentas para a } \\
\text { promoção do cuidado } \\
\text { humanizado }\end{array}$} \\
\hline Equipe multiprofissional determinando a implementação do cuidado humanizado & \\
\hline Formação pessoal e acadêmica interferindo na produção do cuidado humanizado & \\
\hline Potencialidade do acompanhante e seus limites & \\
\hline
\end{tabular}

Fonte: Dados da pesquisa

Em seguida, elaborou-se uma redação por tema, com apresentação e interpretação dos resultados (Minayo et al., 2016).

A pesquisa foi aprovada em 04 de setembro de 2018, pelo Comitê de Ética da instituição pesquisada, sob o parecer de $n^{\circ}$ 2.872.218 e Certificado de Apresentação para Apreciação Ética (CAAE): 95474418.4.0000.5413. Para manter o sigilo dos participantes e salvaguardar seus nomes, os discursos foram codificados por meio das siglas: ASS - médico assistente ginecologista e obstetra; ANE - médico anestesiologista; RES - médico residente de ginecologia e obstetrícia; ENF - enfermeiros; ATE - auxiliar e técnico de enfermagem. 


\section{RESULTADOS}

\subsection{Caracterização dos profissionais da saúde}

Foram entrevistados 24 profissionais de saúde. Desses, nove (38\%) eram médicos ginecologistas e obstetras, seis (25\%) auxiliares ou técnicos de enfermagem, quatro (16\%) residentes de ginecologia e obstetrícia, três (13\%) enfermeiros, e dois $(8 \%)$ médicos anestesiologistas.

No que diz respeito ao sexo, 17 (70\%) dos entrevistados pertencem ao sexo feminino e sete (30\%) ao masculino. A equipe de enfermagem é do sexo feminino em sua totalidade. Quanto aos residentes, três (75\%) são do feminino e um (25\%) é do masculino. Dentre os ginecologistas e obstetras, cinco (55\%) são do masculino e quatro (45\%) do feminino. No que se refere aos médicos anestesiologistas, um (50\%) é do masculino e um (50\%) do feminino $(50 \%)$.

\subsection{Apresentação dos Temas}

\subsubsection{Nuances do Cuidado Humanizado}

Os conceitos de cuidado humanizado às gestantes, parturientes e puérperas mencionados pelos profissionais da saúde perpassam por algumas nuances. Um entendimento sobre cuidado humanizado é a compreensão da mulher em suas diferentes dimensões, sejam elas biológicas, psicológicas, sociais, culturais e econômicas, não reduzindo-as, apenas, ao aspecto biológico ou patológico.

"Antes dela ser uma gestante, antes dela ser uma puérpera, ela é uma mulher e a gente tem que respeitar isso. Lembrar que tem um ser humano ali do outro lado." ASS8.

Outro entendimento é o respeito às decisões, vontades e necessidades da mulher, devendo ser considerados seus direitos, autonomia e privacidade. Alguns profissionais citaram a palavra "individualizado" para ressaltar essa ideia e uma única menção foi feita ao termo "protagonismo", condição em que o respeito às preferências da paciente é ampliado e ela é colocada como condutora da sua gestação, parto e puerpério. Houve a ressalva de que os desejos da paciente devem ser o centro do cuidado, porém existem limitações. As necessidades das mulheres são consideradas e a capacidade técnica do profissional compõe a tomada de decisão. 
"O parto humanizado vem daí, de atender as necessidades da paciente, de não atender a necessidade do médico. Se 'ah, a paciente precisa ficar mais duas horas esperando dilatar', é a necessidade dela e do recém-nascido, que é a peça mais vulnerável da situação. E não de fazer aquilo que é conveniente." ASS9.

“[...] Então, um cuidado humanizado é um cuidado individualizado. O médico tem que levar em consideração aquela mulher, a história clínica dela, as vontades dela. [...] ela se sente respeitada e protagonista daquilo que está acontecendo com ela [...] Ninguém está falando em fazer só o que a mulher quer. Nós temos a competência técnica para identificar os problemas e indicar uma cesárea ou de contraindicar um parto normal, por exemplo. Só que a gente tem que respeitar a vontade da mulher." RES2.

“Eu considero o parto humanizado, o parto da maneira que a mulher desejar. Seja uma cesárea. Pode ser, por que não? Ela não quer fazer o parto vaginal? Não tem problema, mas ele pode ser humanizado e não simplesmente uma técnica cirúrgica que você esquece que ali tem um ser humano que pariu mais um ser humano. Que ali tem toda uma família." ENF2.

Os entrevistados mencionaram que um cuidado humanizado está na capacidade dos profissionais em acolher, informar, orientar, discutir e tomar decisão compartilhada com as pacientes. Essa capacidade mostrou-se fundamental em todos os momentos: consultas de pré-natal, internação, momento do parto, nascimento do bebê e cuidados puerperais. Surgiram reflexões acerca das orientações realizadas às pacientes. A primeira delas, diz respeito à valorização do pré-natal como um momento decisivo para propiciar um cuidado humanizado. A segunda, refere-se à desmistificação do puerpério, que deve ser encarado sob a perspectiva da maternidade real.

"A paciente tem que saber o que está acontecendo com ela. Então, você tem que informar e sempre discutir as intervenções com ela. Eu acho que falta muito tudo isso. Às vezes, o médico vem naquela posição hierarquizada, verticalizada e fala pra você o que você tem que fazer." RES2.

Aparece o cuidado humanizado como aquele que deve estar embasado em evidências científicas e que a capacitação dos profissionais deve ser permanente. Os profissionais de saúde demonstraram preocupação em evitar intervenções desnecessárias durante o préparto, parto e pós-parto. Foi mencionado o termo "violência obstétrica" e a importância de ferramentas institucionais baseadas na literatura como, por exemplo, os protocolos, para garantir a realização de procedimentos comprovadamente benéficos para a mulher e o bebê. Foi exposto que as relações de poder podem interferir na tomada de decisão e que, nem sempre, estão pautadas em evidências, mas nas necessidades dos profissionais. 
“A gente peca por não se atualizar, por não ver que existem formas diferentes de abordagem. Não é porque você aprendeu na faculdade que tem que fazer daquele jeito e que vai ser daquele jeito pra sempre." RES2.

"Cuidado humanizado é fazer aquilo que é correto e que está prescrito em literatura. Várias barbaridades que nós vemos por aí não estão baseadas em literatura nenhuma, mas, sim, em um senso de autoridade ridículo de gente que está aí há muito tempo e acha que é tudo certo [...] Eu já vi casos nítidos de violência obstétrica, casos que eu me sinto até mal de citar. Felizmente, meus relatos dessas atividades tenebrosas são poucos. Onde eu tive minha formação era muito protocolado, era tudo muito sério, rígido. Não tinha espaço pra alguém chegar e fazer uma loucura da própria cabeça." ASS9.

Além disso, foi considerado que se trata de oferecer um cuidado afetuoso e educado, e a empatia pode ser utilizada como ferramenta para isso. Entretanto, não é um consenso e foi destacado que o cuidado humanizado vai além de demonstrar carinho no estabelecimento da relação entre o profissional de saúde e a paciente. Mostra-se problemática a ideia de "tratar as pessoas como você gostaria de ser tratado", porque essa é uma percepção individual e a inconformidade entre as preferências da paciente e as do profissional pode resultar em situações de desrespeito.

"Demonstrar carinho pelo o que você faz, demonstrar cuidado, zelo, proteção, não deixando que se perca essa sensibilidade de cuidar com carinho, cuidar com amor. Isso é humanizar. É cuidar bem, fazer bem." AET6.

"As pessoas têm um conceito geral de que fazer um cuidado humanizado é simplesmente você ser carinhoso, falar de uma forma adequada, ser empático. Parece que é só ir seguindo essas regras sabe? Que é ter uma boa conduta ou um bom relacionamento. Eu acho que faz parte, mas eu acho que é muito mais do que isso." RES1.

Menciona-se, também, uma outra perspectiva sobre o cuidado humanizado, sendo considerado que é aquele que possui acesso a exames.

"É você assistir essa mulher e a sua criança de uma maneira sensata, proporcionando a ela o melhor que você tem na medicina. Que ela tenha acesso a todos os exames necessários." ASS5.

Evidencia-se que o médico é indispensável na promoção do cuidado humanizado, no caso, a figura do obstetra, pediatra e anestesiologista.

"Pra mim, o parto humanizado é o médico, o pediatra, o anestesista. Seja alto, baixo, cirúrgico baixo. Isso é um parto humanizado. Ponto." ASS4.

Por fim, as entrevistas criaram um espaço propício para a metalinguagem da pesquisa, ao causar a reflexão dos próprios profissionais de saúde sobre o termo "humanizado" como definidor do cuidado. Houve, não só a objeção a essa nomenclatura, mas também a 
predileção por ela. Embora realizada a reflexão sobre a terminologia e a prática obstétrica, percebe-se que os profissionais consideram ser um desafio a possibilidade de modificar as ações do cuidado.

“Tudo que eu fiz foi tudo errado, sempre fui desumano. Quando vejo esse termo 'humanização' é essa a sensação que eu tenho. Eu acho que é um termo errado. Não estamos humanizando o parto. Toda vez que eu vejo esse termo em tudo quanto é lugar, sinto que tudo que fiz na minha vida eu fui um crápula. Não sei qual é o termo que deveria ser usado, nunca parei pra ver isso, mas tenho uma crítica muito grande a ele." ASS5.

"Nós chegamos num ponto em que tudo está muito medicalizado. Então, a gente precisa voltar a humanizar, sim. Eu acho que o termo ainda é muito válido, não dá pra você mudar o termo agora. Eu já ouvi outros termos do tipo: 'assistência moderna' ou 'parto do século XXI'. Mas, gente, é humanizar! Porque a gente vê uma assistência aqui que realmente não é humana. Você separar o bebê da mãe no momento que nasce, você obrigar ela a ter o parto numa posição que ela não quer, você cortar o períneo dela pra ter um parto, você empurrar a barriga dela pro neném nascer. Isso não é humano, então a gente tá tendo que humanizar de novo." RES2.

\subsubsection{Ferramentas para Promoção do Cuidado Humanizado}

Sob a perspectiva de alguns entrevistados, a estrutura organizacional do hospital se relaciona com a viabilização de um cuidado humanizado.

"Eu acho que a estrutura não diz se eu vou ter um parto humanizado ou não, mas ela facilita. Às vezes, eu tenho que fazer revezamento de chuveiro porque eu estou com duas pacientes no trabalho de parto e as duas querem ir pro banho porque o banho alivia a dor. Mas eu não consigo proporcionar isso para as duas." RES2.

\section{Afirma-se que uma equipe multidisciplinar coesa e consciente de sua função é determinante para facilitar a implementação de um cuidado humanizado.}

"No cuidado humanizado, não adianta eu sozinho querer fazer. Dentro de uma instituição tão grande, fazer uma ação, quando, às vezes, um colega da enfermagem ou da assistência social, ou da limpeza ou mesmo outro colega médico faz uma coisa totalmente diferente. Isso desconstrói todo o processo." RES1.

O aspecto acadêmico foi contemplado, trazendo uma contraposição entre os profissionais. Há os que defendem que a humanização é intrínseca à pessoa e os que sustentam que ela pode ser aprendida. Destacam que a estratégia de Educação Permanente em Saúde (EPS) é central para que as mudanças possam ocorrer nas práticas em saúde. Além disso, sinalizam que precisa ser adotada como atividade institucional e sem interrupções. 
“O cuidado humanizado vem de berço, vem da própria pessoa, do próprio eu da pessoa. Não tem como, é ela que vai conseguir ser atenciosa, ser empática. Não é uma coisa que se ensina, não dá pra seguir um checklist." RES1.

"Faltam profissionais com vontade de desenvolver a humanização. Eles não vão vir com isso. A gente precisa trazer a necessidade disso pra eles com uma capacitação, com uma orientação nesse sentido. Não adianta querer que eles sejam humanizados se eles nem sabem o que é isso." ASS2.

"Acho que a gente precisa melhorar, com educação, né? Com educação permanente, que é primordial e que a gente ainda não conseguiu ter. Às vezes tem, fica um tempo e aí por conta da demanda não tem mais." ENF1.

Aparece a importância da presença do acompanhante nesse momento da vida da mulher. No entanto, é apontada a deficiência de estrutura física para a viabilização dessa estratégia e assinalado que aqueles que assumem esse compromisso devem ser qualificados para tanto. Além disso, é trazida a problematização de quem deve ser o acompanhante, com a defesa de que o companheiro/marido não seria indicado, o que revela a dificuldade do profissional em compreender o papel e as capacidades do homem no contexto do parto e a atribuição somente às acompanhantes mulheres de viver e apoiar esse momento.

"O mais importante que eu vejo aqui nessa humanização é o pai ou acompanhante que fica junto com a mãe o tempo todo. Que fica ali de mão dada, assiste todo o trabalho de parto e fica tudo mais tranquilo." ATE6.

"Eu até brinco com os acompanhantes, que pai é péssimo pra acompanhar parto, pai é o pior acompanhante. Se você olhar nos filmes antigos, quem está acompanhando a parturiente? A mãe, a irmã, a prima, a parteira. Homem não entra, homem não foi feito pra ver mulher parindo." ASS4.

"O marido tem que participar, porque quando você deixa o marido de fora desse processo, como é que vou querer que ele ajude essa mulher na hora que ela tiver ganhado nenê, que ajude no momento que ela precise?" ASS8.

\section{DISCUSSÃO}

Foi identificado que há uma variedade de compreensões acerca do tema, em grande parte, conferida a distintas abordagens teóricas e metodológicas. Em vista disso, escolhemos conduzir essa investigação tendo como foco apenas a concepção de maternidade e de nascimento, com a preocupação de identificarmos as definições de humanização do parto e nascimento, sob a perspectiva dos profissionais de saúde. 
Os resultados da pesquisa revelam que o cuidado humanizado possui diversas concepções e não são, necessariamente, semelhantes e complementares, podendo ser distintas e conflitantes. Essa multiplicidade de definições explicita o tensionamento de forças, já ressaltado pelo MS (2017b), entre o modelo biomédico hegemônico e a reivindicação por um cuidado humanizado, que tem se instalado na prática obstétrica e neonatal. Os resultados são especialmente importantes, pois refletem o cuidado ao trabalho de parto, parto e pós-parto oferecido pelos profissionais de saúde em um hospital universitário e acaba por revelar a persistência de uma visão resistente às evidências científicas, fragmentada, despersonalizada, vinculada à disputas profissionais para realizar o cuidado obstétrico e com prevalência de um modelo biomédico.

Evidencia-se que a implementação de projetos que visam a mudança de práticas profissionais, como o Projeto Apice On, requer estratégias que promovam a discussão sobre as práticas executadas e sobre os motivos que mobilizam as pessoas a considerarem as atitudes, os valores e a conduta ética nas ações realizadas. Nessa direção, o estabelecimento do espaço de Educação Permanente em Saúde (EPS) pode ser uma das estratégias que favorecem os processos de mudanças. Uma vez que a EPS é uma política pública que vem sendo implementada no Brasil desde 2003 e que apoia os processos de mudanças nas práticas em saúde (MS, 2004).

A medicalização do parto é aqui representada por dois núcleos de sentido. Um deles, concebe a humanização unicamente como o acesso a exames e, o outro, como a presença indispensável de médicos no trabalho de parto, seja ele de baixo ou alto risco. Revela-se, portanto, o entendimento restrito de humanização, distanciado da integralidade no cuidado ao sujeito, assim como, a permanência de um caráter tecnocrata. Essa perspectiva demonstra a incompatibilidade com o que é preconizado pela OMS e MS, pois as entidades questionam o predomínio do profissional médico na assistência e recomendam a inclusão de enfermeiras obstétricas e obstetrizes na condução do parto de baixo risco, por diminuir intervenções desnecessárias e aumentar a satisfação das mulheres com a experiência do parto, sem causar prejuízo aos indicadores maternos e perinatais (OMS, 2014).

Disputas de poder entre categorias profissionais envolvidas na cena do parto contribuem para que haja uma resistência à incorporação de recomendações cientificamente embasadas e internacionalmente validadas (Vilela, 2017). A constatação também foi evidenciada no estudo de Diniz et al. (2018), no qual identificou que os hospitais 
universitários estão entre os locais mais resistentes à mudança. O que é paradoxal, pois o entendimento comum seria que as mudanças deveriam iniciar nesses espaços por serem mais avançados em termos de conhecimento científico, fundamentação ética, melhores práticas e formação de novos profissionais. O progresso nos lugares que deveriam ser os primeiros a inovar e promover as mudanças necessárias é dificultado pela inércia dentro das grandes instituições, pela dificuldade de traduzir em prática os direitos humanos, pelo controle do conhecimento e da prática do trabalho de parto por parte dos médicos, e pela ampla e oculta violência de gênero nas universidades e na assistência médica. Vilela (2017) ainda acrescenta que os profissionais que atuam nos hospitais universitários, são também professores. Dessa maneira, tornam-se referência nesses ambientes de aprendizagem aos graduandos, que são, especialmente, permeáveis. Logo, ao reproduzir e ensinar essas práticas de ensino obsoletas e não embasadas, transmitem seus valores.

$\mathrm{Na}$ investigação, observamos conflito em relação à presença dos companheiros/maridos como acompanhantes, sendo identificado também por Vilela (2017). É uma situação comum os serviços não permitirem a entrada deles no ambiente do parto. Assim, superar preconceitos e discriminação quanto à presença dos homens nas maternidades pode ser indicador de uma cultura cidadã. Especialmente porque é preciso reconhecer a diversidade de significados que orientam as escolhas de acompanhante pelas gestantes e evitar transformar essa participação em imposição de valores. Valadão \& Pegoraro (2020) evidenciaram que a presença do acompanhante em todos os momentos nem sempre acontece, mesmo sendo um direito assegurado por lei no Brasil, e destacaram que os desejos das mulheres, muitas vezes, não foram respeitados pela equipe de saúde.

Desse modo, é possível inferir que há espaço para mudança nos hospitais ligados a instituições de ensino, com a substituição da medicalização do parto e suas intervenções desnecessárias, dolorosas e iatrogênicas, pelo fortalecimento e respeito à fisiologia da mulher, ao seu protagonismo e à sua autonomia. É necessário vencer a cultura machista do país, que vê como natural a situação indigna a que as mulheres são expostas no momento de parir. Essas transformações são urgentes, enfaticamente demonstradas por muitas pesquisas científicas e reivindicadas pela sociedade civil (Vilela, 2017).

\section{CONCLUSÃO}

A pesquisa qualitativa possibilitou revelar as concepções dos profissionais de saúde sobre a humanização do cuidado no pré-parto, parto e puerpério em um hospital de grande porte 
que realiza a formação na graduação e pós-graduação. As concepções dos profissionais foram reveladas por meio das etapas desenvolvidas pelos pesquisadores, seguindo os momentos da análise temática.

Apesar do hospital analisado integrar o Projeto Apice On, as estratégias de sua implementação necessitam ser revistas, pois existem aproximações e distanciamentos das práticas de humanização que embasam o projeto. As práticas de humanização são tímidas, bem como a apreensão e assimilação do conceito de humanização pelos profissionais de saúde, uma vez que não refletem sobre o trabalho prestado, não tendo, assim, potencialidade para viabilizar os processos de mudanças. Isso resulta em uma formação, atenção e gestão ainda incapazes de produzir um impacto consistente na educação em saúde para profissionais de saúde e mulheres, no respeito aos direitos humanos, na defesa da ciência como princípio da prática, em produção de pesquisas socialmente referenciadas, e na aproximação da academia aos temas sensíveis dos movimentos sociais.

Foram identificadas ferramentas para a promoção do cuidado humanizado. Sendo elas: estrutura organizacional hospitalar adequada, equipe multidisciplinar consciente de sua função, formação profissional e presença de acompanhante. Mediante essa constatação, a Educação Permanente em Saúde deve ser incorporada como uma estratégia de reflexão e reconstrução das práticas em saúde. É uma aliada para potencializar a implementação e ampliação dessas quatro ferramentas para que ocorra, de fato, uma transformação do processo de trabalho e cuidado oferecido, em consonância com a humanização do parto e nascimento.

Entende-se que uma limitação da pesquisa está em não ter entrevistado gestantes, puérperas e familiares, pois a humanização deve ser percebida, sentida e compreendida significativamente não só pelos profissionais de saúde, mas também por aqueles que são cuidados. Dessa maneira, há a necessidade de ampliar a investigação com as usuárias do serviço e seus familiares.

\section{REFERÊNCIAS}

Ayres, J. R. C. M. (2009). Cuidado: trabalho e interação nas práticas de saúde (1st ed.). Rio de Janeiro: CEPESC.

Bourguignon, A. M., \& Grisotti, M. (2018). Concepções sobre humanização do parto e nascimento nas teses e dissertações brasileiras. Saúde e Sociedade, 27(4), 1230-1245. DOI: 10.1590/s0104-12902018170489 
Brasil. Ministério da Saúde. Portaria no 198/GM/MS, de 13 de Fevereiro de 2004. Institui a Política Nacional de Educação Permanente na Saúde como estratégia do SUS para formação e desenvolvimento de trabalhadores para o setor e dá outras providências. Brasília.

Brasil. Ministério da Saúde. Portaria n 569/GM/MS, de 01 de junho de 2000. Institui o Programa de Humanização no Pré-natal e Nascimento. Brasília.

Brasil. Ministério da Saúde. Portaria n 1459/GM/MS, de 24 de junho de 2011. Dispõe sobre a implantação da Rede Cegonha. Brasília.

Brasil. Ministério da Saúde. Secretaria de Atenção à Saúde. Departamento de Ações Programáticas e Estratégicas. (2017a). Apice On: Aprimoramento e Inovação no Cuidado e Ensino em Obstetrícia e Neonatologia. Brasília.

Brasil. Ministério da Saúde. Secretaria de Ciência, Tecnologia e Insumos Estratégicos. Departamento de Gestão e Incorporação de Tecnologias em Saúde. (2017b). Diretrizes nacionais de assistência ao parto normal. Brasília.

Diniz, C. S. G., Rattner, D., d'Oliveira, A. P. L., Aguiar, J. M. de, \& Niy, D. Y. (2018). Disrespect and abuse in childbirth in Brazil: social activism, public policies and providers' training. Reproductive Health Matters, 26(53), 19-35. doi: 10.1080/09688080.2018.1502019

Lansky, S., Souza, K. V. de, Peixoto, E. R. M., Oliveira, B. J., Diniz, C. S. G., Vieira, N. F., Cunha, R. O. \& Friche, A. A. L. (2019). Violência obstétrica: influência da exposição sentidos do nascer na vivência das gestantes. Ciência \& Saúde Coletiva, 24(8), 2811-2824. doi: 10.1590/1413-81232018248.30102017

Lokugamage, A. U., \& Pathberiya, S. D. C. (2017). Human rights in childbirth, narratives and restorative justice: a review. Reproductive Health, 14(17). doi: 10.1186/s12978-016-0264-3

Mendes, Y. M. M. B., \& Rattner, D. (2020). Estrutura e práticas de hospitais integrantes do Projeto Apice ON: estudo de linha de base. Revista de Saúde Pública, 54, 23. doi: 10.11606/s1518-8787.2020054001497

Minayo, M. C. S. (2014). O desafio do conhecimento: pesquisa qualitativa em saúde (14a ed.). São Paulo: Hucitec.

Minayo, M. C. S., Deslandes, S. F., \& Gomes, R. (2016). Pesquisa social: Teoria, método e criatividade (1st ed.). Rio de Janeiro: Vozes.

Organização Mundial da Saúde. (2014). Declaração sobre prevenção e eliminação de abusos, desrespeito e maus-tratos durante o parto em instituições de saúde. Genebra.

Picheth, S. F., Crubellate, J. M., \& Verdu, F. C. (2018). A transnacionalização do parto normal no Brasil: um estudo das últimas cinco décadas. História, Ciências, Saúde-Manguinhos, 25(4), 1063-1082. doi: 10.1590/s0104-59702018000500009

Valadão, C. L., \& Pegoraro, R. F. (2020, Janeiro/Abril). Vivências de mulheres sobre o parto. Fractal: Revista de Psicologia, 32(1), 91-98. doi: 10.22409/1984-0292/v32i1/5739

Vilela, M. E. A. (2017). Atenção ao parto e nascimento em hospitais de ensino: o que dizem as mulheres (Dissertação de Mestrado). Fundação Oswaldo Cruz, Instituto Nacional de Saúde da Mulher, da Criança e do Adolescente Fernandes Figueira, Rio de Janeiro, RJ, Brasil.

World Health Organization. (2018). WHO recommendations: intrapartum care for a positive childbirth experience. Geneva. 